\title{
Kelsen e o trilema de Münchhausen
}

\author{
Inácio Helfer ${ }^{1}$ \\ Leandro Konzen Stein ${ }^{2}$
}

\begin{abstract}
Sumário: Introdução; 1. A prisão do trilema de Münchhausen; 2. Ordenamento Jurídico, Validade e Eficácia: a pureza formalista do pensamento kelseniano - influências (neo) kantianas e (neo)positivistas; 3. Função Política da Teoria Pura do Direito: o fechamento do sistema e a Grundnorm - críticas à teoria kelseniana; 4. A Teoria Pura do Direito e o Trilema de Münchhausen; Conclusão; Referências.
\end{abstract}

Resumo: O pensamento de Hans Kelsen é um contributo dos mais importantes para a ciência jurídica contemporânea, mormente com advento de sua obra primordial, Teoria pura do direito, na qual lança as bases de um edifício teórico que irá ser rapidamente reconhecido como uma das maiores construções epistemológicas e metodológicas acerca do Direito. Contudo, com o surgimento de novos paradigmas epistemológicos ancorados em posições antimetafísicas e antipositivistas, incoerências se apresentam, fazendo-se necessárias as críticas. É nesse ponto que, tendo por base a obra Tratado da razão crítica de Hans Albert, pretendemos analisar a fundamentação kelseniana sobre a validade do direito positivo estatal, em especial sob o prisma do trilema de Münchhausen enunciado por Albert, para avaliar sua pertinência.

Palavras-chave: Hans Kelsen; fundamentação suficiente; trilema de Münchhausen; Hans Albert.
Abstract: The Hans Kelsen's thought is one of the most important contributions to the contemporary legal science, especially with the upcoming of his main work, Pure Theory of Law, in which he launches the groundings of a theoretical building that will be quickly recognized as one of the most important epistemological and methodological construction about Law. However, since the new epistemological paradigms connected with anti-metaphysical and anti-positivist positions, incoherencies are showed, making necessary some critics. In this point, connected with the work "Treatise on critical reason", by Hans Albert, we intend to analyze the Kelsen's grounding about State Law's validity, especially with the prism of Munchausen's trilemma enounced by Albert, to judge its pertinence.

Keywords: Hans Kelsen; sufficient ground; Münchhausen's trilemma; Hans Albert.

\section{Introdução}

\author{
Hans Kelsen é um autor que ainda hoje provoca controvérsias. \\ Tais controvérsias não são fortuitas, uma vez contar o autor ainda
}

\footnotetext{
1 Doutor em Filosofia e professor na UNISC e UNISINOS.

2 Mestrando em Direito pela UNISC. Bolsista CAPES.
} 
com grande projeção entre juristas, sendo, não raro, citado em obras doutrinárias brasileiras.

Kelsen ainda é, por outro lado, alvo de constantes críticas, o que denota que sua teoria ainda não está morta, não pelo menos como parâmetro de teoria criticável (além de inspiração velada de teorias modernas e pós-modernas). A teoria pura do Direito parece que ainda vai sobreviver por muito tempo. Pelo menos enquanto os ideais em que se baseou forem atraentes aos seus juristas. Esses ideais, como o mito da linguagem técnica, da neutralidade, da metalinguagem e da clausura do Direito, prestam-se ainda a satisfazer os fetiches teóricos de abordagens rigorosas só em aparência, mas que não assumem a discussão de fundo. Por outro lado, abordagens irracionalistas, desvinculadas da necessidade de fundamentação, ou fundamentadas em abordagens esteticistas, decisionistas, teológicas, ou metafísicas em geral, em nada contribuem, uma vez que não são uma alternativa viável.

Hans Albert é um autor crítico-racionalista da linha de Popper. Como tal, ainda assume um ranço de positivismo, que se traduz, na seara epistemológica, em um certo decisionismo, além de vincular-se a uma perspectiva semântica. Critica, em vista de seu tempo, as concepções que de alguma maneira se fundamentam na lógica. Todavia, hoje, várias são as concepções teóricas que, longe de metafísicas ou irracionalistas, rechaçam veementemente a lógica e os semanticismos. São as concepções pragmáticas. Nos limites deste trabalho - espacial e temporalmente limitado a aspectos pontuais da experiência científica e filosófica acerca do Direito nos séculos XX e XXI - o problema e hipótese trafegaram em torno das aplicações do trilema de Münchhausen (de autoria de Albert) à teoria kelseniana, mostrando suas incoerências. Uno actu, demonstra-se a excelência da abordagem de Hans Albert, a qual, todavia, não atinge concepções pragmáticas - uma vez que estas estão despidas do ideal de logicidade absoluta.

\section{A prisão do trilema de Münchhausen}

O conhecimento, em toda história da humanidade, apresenta-se por meio de teorias as quais pretendem, de alguma maneira, explicar o mundo. Para isso, sempre se exigiu que se explicasse o porquê de um modelo ou outro explicar mais coerentemente a realidade, ou ter um fundamento de 
validade: este é o problema da fundamentação. Porque fundamentado, o conhecimento científico seria superior ao senso comum.

O pensamento ocidental, de acordo com Hans Albert, estaria calcado na possibilidade de descoberta de uma fundamentação suficiente, isto é, um argumento claro e ordenado capaz de, por sua própria racionalidade interna, gerar uma adesão geral e possibilitar a geração de consequências. Estas consequências estariam automaticamente fundamentadas, uma vez fundamentado o argumento primeiro:

Com isto parece estar concluído o processo de conhecimento para este campo. Os problemas estão solucionados; suas soluções deixam-se aprender, transmitir e aplicar, sem que precisem novamente ser colocadas em questão. ${ }^{3}$

Cabe ressalvar, inicialmente, que Hans Albert dirige suas críticas ao pensamento ocidental como um todo, isto é, engloba matrizes de pensamento distintas, tais como a matriz analítica, a hermenêutica e a dialética (excluindo o racionalismo crítico, posição a que se filia). Contudo, o objetivo deste trabalho está circunscrito à possibilidade de aplicação dessa crítica a apenas um autor da matriz positivista-analítica: Hans Kelsen. Isto quer dizer que, com relação às outras matrizes, o exame da procedência da crítica de Hans Albert ainda está por ser avaliado.

Uma fundamentação para a ciência de matriz analítica, vai ocorrer a partir de uma dedução lógica, ou seja, de uma premissa, deduzem-se conclusões. O processo de "dedução" vai ocorrer com a ajuda de regras lógicas. Uma regra lógica, por exemplo, é a de que um enunciado sem conteúdo (analítico) só pode gerar enunciados sem conteúdos. No sistema kelseniano de pensamento, por exemplo, a cadeia lógica de argumentação é estruturada a partir de uma fórmula de imputação, i. é, de um dado fato $\mathrm{X}$ decorre uma consequência $Y$, consequência essa que é garantida pelo poder coativo do Estado. Essa estrutura (se X, Y) é descrita em um mandato que é autorizado por um mandato superior e assim por diante. Enunciados com conteúdo, todavia, podem gerar enunciados analíticos e de conteúdo (se matar, 6 a 20 anos; poder-se-ia analisar essa proposição tanto sob o ponto de vista lógico-formal quanto pelo ponto de vista lógico-material).

ALBERT, Hans. Tratado da razão crítica. Tradução de Idalina Azevedo da Silva, Érika Gudde e Maria José P. Monteiro. Rio de Janeiro: Tempo Brasileiro, 1976, p. 24. 
Voltemos, então, ao problema da fundamentação. Que papel pode desempenhar aqui a dedução lógica? De acordo com o princípio acima enunciado, podemos partir do fato de que a finalidade do procedimento da fundamentação deve constituir-se, em cada caso, em assegurar a verdade das concepções em questão e, dessa forma, a dos enunciados com os quais elas se formulam [...] Procura-se a fundamentação de uma convicção - ou a fundamentação de um conjunto de enunciados - através do remetimento a fundamentos seguros - e dessa forma indubitáveis - através de meios lógicos, ou seja, com a ajuda de deduções lógicas, e de tal maneira que todos os componentes do referido conjunto de enunciados resultem dessa base mediante conclusões lógicas. ${ }^{4}$

$\mathrm{Ou}$ seja, fundamentar um complexo de enunciados significa fundamentar a base referencial desses enunciados. Isto é, um sistema jurídico, estruturado logicamente, terá de ser fundamentado em algo, seja em um início, seja em uma circularidade, seja em um ponto final. A não ser que se assuma uma postura irracionalista, esteticista, ou o que valha (evitando, assim, o problema da fundamentação, ao invés de resolvê-lo uma posição dogmática, portanto, uma vez que tal solução provoca fuga da argumentação), uma teoria (mesmo que não analítica ou "lógica") terá de resolver o problema da fundamentação. Para Hans Albert, contudo, esta empreitada é impossível, pois qualquer argumentação necessariamente incorrerá em uma série de inconsistências a que denomina trilema de Münchhausen. Este consiste em:

1 um regresso infinito, que parece resultar da necessidade de sempre, e cada vez mais, voltar atrás na busca de fundamentos, mas que na prática não é passível de realização e não proporciona nenhuma base segura;

2 um círculo lógico na dedução, que resulta da retomada, no processo de fundamentação, de enunciados que já surgiram anteriormente, como carentes de fundamentação, e o qual, por ser logicamente falho, conduz do mesmo a nenhuma base segura; e finalmente,

3 uma interrupção do procedimento em um determinado ponto, o qual, ainda que pareça realizável em princípio, nos envolveria numa suspensão arbitrária do princípio da fundamentação suficiente. ${ }^{5}$

ALBERT, 1976, p. 26.

ALBERT, 1976, p. 26-27. 
A primeira forma de fundamentação é claramente identificável como inconsistente. Uma teoria jurídica que buscasse fundamentar-se regredindo infinitamente estaria evidentemente fadada ao fracasso, visto a sua total impossibilidade.

O segundo ponto refere-se ao círculo lógico, isto é, a fundamentação será estribada em uma argumentação recursiva, onde um argumento inicia o processo de deduções cujo final será esse mesmo argumento carente de fundamentação, ou seja, não se fundamenta o fundamento. Esta forma de validação está presente, hodiernamente, em algumas proposições do tipo: "A Constituição é legítima porque é a lei maior do ordenamento", 6 ou "O Supremo Tribunal Federal é o mais alto tribunal da República", "Devemos obedecer esta norma porque é lei". ${ }^{8}$

O terceiro tipo de proposição é mais comumente visto nas fundamentações teóricas, tanto no plano da Filosofia como no plano científico:

Costuma-se em relação a enunciados nos quais se está disposto a interromper o processo de fundamentação, falar de auto-evidência, de autofundamentação, de fundamentação no conhecimento imediato - na intuição, na vivência ou experiência - ou descrever de outra maneira que se está disposto a interromper o regresso da fundamentação em um determinado ponto, e conseqüentemente, suspender o postulado da fundamentação neste ponto, o qual é denominado de ponto arquimédico do conhecimento. ${ }^{9}$

A interrupção gera o efeito de segurança necessário para que ocorra a continuação da argumentação; assim, “[...] a nossa terceira possibilidade se resume naquilo que não se deveria esperar na solução do problema da fundamentação: a fundamentação mediante o recurso a um dogma". ${ }^{10}$ Trata-se da criação de um ponto de início, um ponto arquimédico nos dizeres de Hans Albert. Este ponto de início tem de gerar uma impressão ao ouvinte de um "mal necessário ou de inocuidade". ${ }^{11}$

6 Ou seja, uma ideia de que a Constituição se fundamenta por ela mesma, e não em processos histórico-sociais de decisão.

7 É uma oração que se fundamenta em si mesma, i.e, se é supremo é o mais alto.

8 Sem indagar acerca da legitimidade da norma.

9 ALBERT, 1976, p. 27.

10 ALBERT, 1976, p. 27, grifos do autor.

11 ALBERT, 1976, p. 27. 
Pretendemos, a partir do delineamento do trilema de Münchhausen, analisar o pensamento kelseniano e verificar se e como o mestre de Viena recai nos erros de fundamentação absoluta configurados a partir da visão de H. Albert. ${ }^{12}$ Nesse sentido, antes dessa análise, faz-se mister uma retomada da obra kelseniana, de suas influências, bem como a análise de seu pensamento.

\section{Ordenamento Jurídico, Validade e Eficácia: a pureza formalista do pensamento kelseniano - influências (neo) kantianas e (neo)positivistas}

Kelsen, em sua obra principal, Teoria Pura do Direito, ${ }^{13}$ intenta criar uma teoria sobre o direito baseada na qualificação desse enquanto ciência, através da identificação de seu objeto - as normas objetivas eficazes postas pelo legislador ou pelo monarca. Essa identificação das normas enquanto objeto da ciência jurídica leva muitas vezes a se conceituar o modelo kelseniano como normativista.

Contudo, o esquema epistemológico kelseniano é muito mais complexo que essa mera redução do objeto do direito às normas e sua

12 Todavia, existem hoje argumentações que superam de maneira não metafísica a prisão do trilema de Münchhausen, como a pragmática transcedental de Karl-Otto Apel. Estas, contudo, não serão abordadas de forma específica. É o que pensa, por exemplo, Manfredo Araújo Oliveira: "É absolutamente fundamental neste contexto compreender o que se passa numa reflexão transcendental e detectar a fonte de mal-entendidos. Se considerarmos as objeções de seus opositores (sobretudo hoje os defensores do Trilema de Münchhausen), podemos verificar que seus argumentos têm um pressuposto básico, ou seja, de que aqui se situa a mudança fundamental de paradigma na questão da fundamentação: a fundamentação última, o específico da demonstração filosófica, não é uma demonstração por derivação, mas uma demonstração enquanto explicitação dos pressupostos irrecusáveis de toda argumentação, inclusive aquela em que se articula o Trilema de Münchhausen e, consequentemente, o princípio do falibilismo, pois o estabelecimento do princípio falibilista é impensável sem estes pressupostos. O cerne da argumentação está exatamente no fato de que, quando o cético duvida das regras e dos pressupostos da argumentação, ele se contradiz a si mesmo, pois, para duvidar, ele participa da práxis social do argumentar e enquanto tal tem que reconhecer suas regras constitutivas sob pena dela não se realizar". OLIVEIRA, Manfredo Araújo. Sobre a fundamentação. Porto Alegre: Edipucrs, 1993, p. 75.

13 A partir de agora passaremos a utilizar também a forma abreviada TPD para nos referirmos a essa obra de Hans Kelsen. 
consequente definição como ciência, em função da sua originalidade e da gama diferenciada de influências teóricas que sofre. Iniciaremos apontando as concepções primordiais de seu pensamento a partir das influências que, a nosso ver, foram fundamentais e determinantes da construção metodológica do pensador de Viena.

Dentre elas, cabe ressaltar a influência do pensamento de Immanuel Kant sobre Hans Kelsen, pois o ponto principal em que se funda o pensamento kelseniano, isto é, aquele vetor que irá determinar a função primordial da TPD, que é fundamentar a validade do ordenamento jurídico positivo, parte de uma premissa fundamental kantiana, a divisão entre sein (ser) e sollen (dever-ser). Como assinala Kelsen:

Se o Direito é concebido como uma ordem normativa, como um sistema de normas que regulam a conduta de homens, surge a questão: O que é que fundamenta a unidade de uma pluralidade de normas, por que é que uma norma determinada pertence a uma determinada ordem? E esta questão está intimamente relacionada com esta outra: Por que é que uma norma vale, o que é que constitui o seu fundamento de validade?

Dizer que uma norma que se refere à conduta de um indivíduo "vale" (é "vigente"), significa que ela é vinculativa, que o indivíduo se deve conduzir do modo prescrito pela norma. Já anteriormente, num outro contexto, explicámos que a questão do por que é que a norma vale - quer dizer: por que é que o indivíduo se deve conduzir por tal forma - não pode ser compreendida com a simples verificação de um facto da ordem do ser, que o fundamento de validade de uma norma não pode ser um tal facto. Do facto de algo ser não pode seguir-se que algo deve ser; assim como do facto de algo dever ser não pode seguir que algo é. ${ }^{14}$

Vê-se logo a divisão entre ser e dever-ser presente no pensamento de Hans Kelsen, o que será essencial no estabelecimento de uma ciência do direito pura, isto é, livre de todo empírico (político, social, etc.), visto que sein e sollen são âmbitos dissociados. ${ }^{15}$ Kelsen liga-se profundamente

\footnotetext{
${ }^{14}$ KELSEN, Hans. Teoria pura do direito. 4. ed. Tradução de João Baptista Machado. Coimbra: Armênio Amado Editor, 1979, p. 267.

15 Mas não completamente, como se verá a seguir, devido à influência neopositivista que se fará presente em Kelsen.
} 
a Kant, uma vez que busca a pureza dissociando os enunciados racionaistranscendentais de qualquer problemática fática. ${ }^{16} \mathrm{~A}$ realização de uma conduta jurídica dá-se no plano do pensamento puro, sem qualquer ingrediente fático ou não jurídico:

Da mesma maneira como Kant, que trata de estabelecer racional e aprioristicamente as condições de possibilidade da ciência física, Kelsen trata de fixar as condições formais e necessárias do conhecimento jurídico, dirigida ao conteúdo das normas. ${ }^{17}$

\section{Segundo observa Rocha:}

Nos capítulos iniciais de sua obra mantém pressupostos kantianos, que se mesclam com os neopositivistas, pouco a pouco (cap. sobre ciência do direito). O ideal de pureza implica separar o conhecimento jurídico, do Direito natural, da metafísica, da moral, da ideologia e da política. Por isso, Kelsen tem como uma de suas diretrizes epistemológicas basilares, o dualismo kantiano entre ser e dever-ser, que reproduz a oposição entre juízos de realidade e juízos de valor. Kelsen, fiel à tradição relativista do neokantismo de Marburgo, optou pela construção de um sistema jurídico centrado unicamente no mundo do dever-ser. Tal ênfase acarretou a superestimação dos aspectos lógicos constitutivos da teoria pura, em detrimento dos suportes fáticos do conhecimento. ${ }^{18}$

16 KANT, Immanuel. Crítica da razão pura. São Paulo: Nova Cultural, 2005, p. 53: “Que todo o nosso conhecimento começa com a experiência, não há dúvida alguma, pois, do contrário, por meio do que a faculdade do conhecimento deveria ser despertada para o exercício senão através de objetos que tocam nossos sentidos e em parte produzem por si próprios representações, em parte põem em movimento a atividade do nosso entendimento para compará-las, conectá-las ou separá-las e, desse modo, assimilar a matéria bruta das impressões sensíves a um conhecimento dos objetos que se chama experiência? Segundo o tempo, portanto, nenhum conhecimento em nós procede a experiência, e todo ele começa com ela".

17 WARAT, Luis Alberto. Introdução geral ao direito II: a epistemologia jurídica da modernidade. Tradução de José Luiz Bolzan de Morais. Porto Alegre: Sergio Antonio Fabris Editor, 1995a, p. 135.

18 ROCHA, Leonel Severo. Epistemologia jurídica e democracia. 2. ed. São Leopoldo: Editora Unisinos, 2003, p. 96. 
Contudo, Kelsen não está atrelado a um idealismo que divide de forma determinista e metafísica o mundo do sein do mundo do sollen. $\mathrm{O}$ autor de Viena buscou, por assim dizer, um ponto de equilíbrio entre o puro idealismo e o realismo que não fazia nenhuma distinção entre o ser o dever-ser:

\begin{abstract}
Dentro do quadro da Teoria Pura do Direito, a relação entre validade e eficácia é uma instância do problema mais geral das relações entre Sein e Sollen, ou entre realidade natural e direito. Kelsen afirma procurar uma "via intermediária" entre as posições equivocadas do idealismo e do realismo. O idealismo sustenta a independência absoluta entre validade (Sollen) e eficácia (Sein); o realismo identifica os dois conceitos. ${ }^{19}$
\end{abstract}

Podemos concluir que Kelsen não se filia totalmente à tradição kantiana, pois essa não é a única influência que recebe, visto também estar vinculado ao (neo)positivismo lógico do Círculo de Viena. ${ }^{20}$ Desse modo,

19 BARZOTTO, Luiz Fernando. O positivismo jurídico contemporâneo: uma introdução a Kelsen, Ross e Hart. São Leopoldo: Editora Unisinos, 2000, p. 54.

${ }^{20}$ Entendemos como Positivismo Lógico aquele pensamento que emerge na década de 20 em Viena, tendo forte influência do Primeiro Wittgenstein (Tratactus), bem como de Carnap (The Logical Sintax of Language) e no direito seu maior expoente é justamente Hans Kelsen. Esse movimento surge como uma das frentes em que se operou o Giro Linguístico (ontological turn). Contudo, a nosso ver - por apegar-se a aspectos sintáticosemânticos na sua análise da linguagem, isto é, ficar presa à questão da relação dos signos entre si (sintaxe) e de sua relação com os objetos a que se referem (semântica) - essa "frente" não "entendeu" o giro, pois, conforme Carlos Nieto Blanco, "[...] o aspecto mais importante do giro lingüístico não foi a tese trivial de que os problemas filosóficos são problemas lingüísticos, senão o próprio enfoque segundo o qual a linguagem começou a ser considerada a partir da tradição filosófica e a influência que a linguagem exerceu sobre elas. Desse modo, ainda que as conseqüências pragmáticas do giro lingüístico tenham começado a fazer-se patentes a partir da década de setenta, a novidade, desde o primeiro momento, foi um giro pragmático. A última filosofia de Wittgenstein, a teoria dos atos de fala de Austin, a hermenêutica de Apel, o neopragmatismo do próprio Rorty ou a teoria da ação comunicativa de Habermas caem, pois sobre essa denominação". BLANCO apud STRECK, Lenio Luiz. Hermenêutica jurídica e $(m)$ crise: uma exploração hermenêutica da construção do direito. 5. ed. Porto Alegre: Livraria do Advogado, 2004, p. 170. Cabe referir ainda, com Warat, que "[...] este movimento recebeu diversas denominações: Empirismo Lógico, Filosofia Analítica, Neopositivismo Lógico, Empirismo Contemporâneo e outras". WARAT, Luis Alberto. O direito e sua linguagem. 2. ed. (com a colaboração de Leonel Severo Rocha). Porto Alegre: Sergio Antonio Fabris Editor, 1995b, p. 37. 
Kelsen cria uma teoria que não é nem idealista, nem empirista, capaz de enquadrar o direito enquanto ciência, a partir da delimitação de seu objeto no plano do dever-ser (normas), sem desvencilhar-se do plano do ser, pois esse estaria presente em dois momentos específicos, sendo condições de validade do sistema jurídico; estamos falando da estatuição das normas e da eficácia dessas normas. Assim, há um momento de entrelaçamento entre o dever-ser normativo e o mundo do ser, na estatuição das normas pelo parlamento (ou pelo monarca) e no respeito/aplicação (eficácia) dessas mesmas normas.

Porém, não se deve misturar as coisas, pois a estatuição e a eficácia não se confundem com o fundamento de validade do sistema. Validade, para Kelsen, é a adequação de uma norma à sua norma superior, sendo que o fundamento de validade de uma estrutura escalonada (um sistema) de normas jurídicas situadas no âmbito do dever-ser somente pode ser um elemento desse âmbito, pois uma norma somente pode ser fundamentada por outra norma (autoprodução do direito), pelo fato de que não há transição do ser para o dever-ser. Como aponta Barzotto:

Mas Kelsen adverte para não se confundir condição de validade com fundamento de validade. Fundamento de validade de uma norma só pode ser outra norma. Na há transição do dever ser ao ser. E fundamento último de validade é a norma fundamental. A eficácia, como a estatuição, é apenas uma condição de validade. ${ }^{21}$

Nota-se o artifício utilizado por Kelsen para não resvalar ao realismo (que identifica o ser com o dever-ser, não diferindo validade e eficácia), sem prender-se a um idealismo dogmático (que nega uma ligação do ser com o dever-ser, dividindo-os completamente). O autor consegue essa "proeza" distinguindo condições de validade (estatuição e eficácia) e fundamento de validade (norma superior fundamenta a inferior até a norma fundamental) ${ }^{22}$ do sistema jurídico.

\footnotetext{
21 BARZOTTO, 2000, p. 56-57.

22 A distinção entre validade e eficácia será analisada de forma mais enfática no próximo capítulo, em que se delineará a relação entre ambas sob o prisma da norma fundamental. "Essa distinção entre fundamento de validade e condição de validade é particularmente delicada no nível da constituição. O fundamento da validade desta não é nem a estatuição, nem a eficácia, mas a norma fundamental". BARZOTTO, 2000, p. 57.
} 


\section{Função Política da Teoria Pura do Direito: o fechamento do sistema e a Grundnorm - críticas à teoria kelseniana}

Contudo, Kelsen não consegue se sustentar diante de críticas mais atentas, tanto no que se refere ao fato de que o seu pensamento sempre foi idealista, como pelo fato de que, ao tentar dividir eficácia e validade, acaba, paradoxalmente, por misturá-las, revelando um caráter meramente dogmático de sua teoria e mesmo uma função político-ideológica da norma fundamental enquanto caractere de fechamento/fundamento/ condição de possibilidade do sistema do direito.

$\mathrm{Na}$ verdade, a teoria que constrói é idealista, por diferir conhecimento teórico e realidade, mas ela serve para legitimar um ordenamento jurídico que já está aí, isto é, há uma construção teórica (idealista) para sustentar de modo formal e "neutro" um direito que já é obedecido (eficaz), insistindo em diferir validade e eficácia no plano teórico de modo a legitimar um Direito Estatal já posto. Assim, pode-se vislumbrar que é uma teoria que não peca pelo fato de ser descritiva, mas por criar um fundamento de validade para o poder estabelecido, o que pode cumprir funções de legitimação política. ${ }^{23}$

Do ponto de vista epistemológico, há uma crítica contundente de Luis Alberto Warat que revela o caráter idealista da teoria pura de Kelsen, a partir da não diferenciação entre idealismo (metafísica) e positivismo, visto que, para o autor, esse seria apenas uma forma de idealismo:

Tradicionalmente sustenta-se que Kelsen sofre influência de uma dupla fonte de inspiração em suas idéias metodológicas vertebrais: Kant e o positivismo científico, respectivamente redefinidos pelo neokantismo e o positivismo lógico. A fusão de algumas idéias do kantismo com outras do positivismo determinou um processo dialético entre ambas as posturas, cuja síntese é a teoria pura do Direito. Isto é, um pensamento relativamente distante e reformulado dos pressupostos indicados. Quaisquer que sejam as variantes introduzidas nas diversas versões da teoria pura, durante

\footnotetext{
23 Não se está apregoando o fato de que Kelsen estaria criando sua teoria de modo a legitimar um dado ordenamento, ou com intuito de manter o status quo. Contudo, sua teoria cumpre essa função de forma velada, escondendo uma função ideológica por trás de uma construção epistemológica.
} 
a longa vida de Kelsen, o saldo teórico não deixa de ser um pensamento idealista, e isto porque, tanto o processo positivista do conhecimento (em sua forma experimental ou em sua modalidade lógica) como o racionalismo (em sua forma pré-gnoseológica e dogmática ou transcendental) têm como base a mesma problemática epistemológica, definem a mesma temática fundamental e ao mesmo tempo evitam possíveis relações da teoria com a realidade. Por razões epistemológicas, sustento a tese de que o positivismo é uma forma de idealismo, porquanto diacronicamente define sua problemática através de um movimento duplo: racional e empírico, conceitual e referencial, que, aceitando sua dialética, ao mesmo tempo está desprezando tanto o idealismo puro como o empirismo ingênuo. Conseqüentemente, temos como síntese um idealismo crítico que não admite um conhecimento exclusivamente processado pelo pensamento sem fazer referência à experiência para constituir a razão em fator determinante do conhecimento a partir da experiência; e um positivismo lógico, que se distancia dos dados sensíveis, desembocando em um conceitualismo vazio e formal, que se conforma com um controle sintático da realidade.

A Teoria pura do Direito, ao ser reduzida a um conceitualismo presente tanto no idealismo crítico como no positivismo lógico, consegue eliminar de sua problemática a discussão sobre os fatores co-determinantes da realidade jurídica, como também sobre o papel social e político do Direito e as dimensões ideológicas dos diversos discursos enquanto prática jurídica concreta. ${ }^{24}$

Vislumbra-se o caráter de distanciamento da realidade que assume a teoria kelseniana, com a caracterização de uma visão ancorada basicamente na divisão entre os âmbitos do sein e do sollen, denotando um caráter de busca da "pureza" ${ }^{25}$ através de uma construção metalinguística

${ }^{24}$ WARAT, 1995a, p. 131-132.

${ }_{25}$ Kelsen, ancorado no neopositivismo, pretendia entender o fenômeno jurídico enquanto ciência (pura). Para isso, era necessário delimitar seu campo (sistema) específico, bem como seu objeto: "Quando a si própria designa como 'pura' teoria do Direito, isto significa que ela se propõe garantir um conhecimento apenas dirigido ao Direito e excluir deste conhecimento tudo quanto não pertença ao seu objecto, tudo quanto se não possa, rigorosamente, determinar como Direito. Quer isto dizer que ela pretende libertar a ciência jurídica de todos os elementos que lhe são estranhos. Esse é o seu princípio metodológico fundamental" (KELSEN, 1979, p. 17). Contudo, a teoria não pretende negar as conexões que o direito tem com outros campos de conhecimento, apenas intenta delimitar os 
sobre o real (aqui, o nível de normatividade, dever-ser), outro momento de influência kantiana, visto que Kelsen não nega a complexidade do mundo, buscando uma metalinguagem sobre o jurídico de modo a criar uma teoria capaz de reduzir a complexidade social a partir das concepções herdadas de Russell, como bem aponta Leonel Severo Rocha:

Kelsen, ao contrário do que pensam seus leitores desavisados, por filiar-se à tradição alemã da Teoria do Conhecimento, assume como inevitável a complexidade do mundo em si. Para Kelsen, o social (e o Direito) são devidos às suas heteróclitas manifestações, constituídos por aspectos políticos, éticos, religiosos, psicológicos, históricos e etc. A partir desta constatação é que Kelsen vai procurar, assim como Kant, depurar essa complexidade elaborando um topos científico de inteligibilidade do Direito: uma coisa é o Direito, outra bem distinta é a ciência do Direito. O Direito é a linguagemobjeto, a ciência do Direito a metalinguagem: dois planos distintos e incomunicáveis.

Essa concepção metalingüística do real, criada por Bertrand Russell, para superar os paradoxos lógicos, é utilizadas por Kelsen em vários momentos $[\ldots] .^{26}$

O distanciamento que Kelsen estabelece entre o momento de estatuição (sein) do Direito ${ }^{27}$ e esse já estabelecido (sollen) - no sentido

limites do sistema jurídico, de modo a não se misturarem os sistemas. Nesse sentido, o próprio Kelsen alerta que "Quando a Teoria Pura empreende delimitar o conhecimento do Direito em face destas disciplinas, fá-lo, não por ignorar ou, muito menos, por negar essa conexão, mas porque intenta evitar um sincretismo metodológico que obscurece a essência da ciência jurídica e dilui os limites que lhe são impostos pela natureza do seu objeto". (KELSEN, 1979, p. 17-18).

${ }^{26}$ ROCHA, 2003, p. 72.

27 Que, como se sabe, pode ser um momento delicado e um campo de batalha acirrado, seja através de um processo democrático, como, v.g., o processo constituinte de 1986-88 no Brasil, ou um processo anti democrático, como o golpe militar de 1964 (o que a Kelsen não importa no que se refere à análise do Direito, justamente pela distinção entre ser e dever-ser). Entendemos que distanciar o Direito de seu processo de produção, a partir da divisão entre sein e sollen, carrega consigo um formalismo jurídico perverso no sentido de que tudo que seja enquadrado enquanto direito (encaixe-se no formato Direito - NãoDireito), ao encontrar-se no plano do dever-ser, não é questionado, se for eficaz (um paradoxo, pois a eficácia está situada no nível do sein, ponto que analisaremos a seguir), revelando um forte conteúdo político-ideológico de legitimação do poder constituído: "Uma norma jurídica não vale porque tem um determinado conteúdo [...], mas porque é 
de não se questionar a legitimidade do processo de criação do direito (distanciamento da realidade, idealismo), não sendo essa problemática referente à atividade do jurista, que se deve preocupar apenas em aplicar o direito já existente - esconde uma função política de sua teoria. Para evitar questionamentos dessa natureza, e "limpar" a teoria de tudo que lhe é estranho (o que não é direito), ao mesmo tempo, evitando contato com o plano do ser (empírico, fático), o autor cria um artifício gnoseológico (lógico-transcedental) de modo a fundamentar/validar o direito (a partir do próprio direito): a norma fundamental (Grundnorm).

Na sua concepção teórica, somente direito fundamenta/valida direito, pelo fato de o direito ser um sistema autoprodutivo fechado, ${ }^{28}$ quer dizer, somente uma norma superior fundamenta uma norma inferior; isso não quer dizer, todavia, que o direito seja cego aos conteúdos, pelo contrário, a abertura a conteúdos é irrestrita (e por isso mesmo até objeto de críticas). Por óbvio, que ao chegarmos à norma máxima do ordenamento positivo, isto é, a Constituição, a pergunta que surge é: o que fundamenta a lex superior? Kelsen estabelece uma norma pressuposta formal de modo a evitar a entrada de caracteres estranhos ao sistema jurídico no nível da validade, garantindo, assim, o fechamento do sistema, pois seria uma outra norma (não posta, mas pressuposta) que fundamentaria a norma maior do ordenamento estatal: assim surge a norma fundamental:

criada por uma forma determinada - em última análise, por uma forma fixada por uma norma fundamental pressuposta. Por isso, e somente por isso, pertence ela à ordem jurídica cujas normas são criadas de conformidade com esta norma fundamental. Por isso, todo e qualquer conteúdo pode ser Direito (KELSEN, 1979, p. 273). Como revela Warat, “O postulado da pureza metódica não pode se sustentar na medida em que nos propõe uma cisão retórica entre a produção das significações jurídicas e o conhecimento científico das mesmas. O saber jurídico é um fator determinante da significação no próprio discurso jurídico, que na ação de retorno cumpre funções políticas e ideológicas, determinando as condições materiais da vida social. O papel social do Direito configura-se a partir da análise do poder de seu discurso. Seria uma problemática invertida, pois não questionaria os efeitos sociais dos discursos, senão os efeitos dos discursos na sociedade." (WARAT, 1995b, p. 146).

28 “Conceber o direito como um sistema normativo dinâmico é concebê-lo como um todo fechado pela via da derivação formal, ou seja, uma norma é válida na medida em que foi criada de acordo com outra norma do ordenamento. Esse conceito de validade como 'legalidade do ato de produção' é essencial para 'fechar' o sistema ao mundo exterior, porque, nessa perspectiva, somente o direito pode ser fundamento do direito." BARZOTTO., op. cit., p. 64. 
Como já notamos, a norma que representa o fundamento de validade de uma outra norma é, em face desta, uma norma superior. Mas, a indagação do fundamento de validade de uma norma não pode, tal como a investigação da causa de um determinado efeito, perder-se no interminável. Tem de terminar numa norma que se pressupõe como a última e a mais elevada. Como norma mais elevada, ela tem de ser pressuposta, visto que não pode ser posta por uma autoridade, cuja competência teria de se fundar numa norma ainda mais elevada. A sua validade já não pode ser derivada de uma norma mais elevada, o fundamento da sua validade já não pode ser posto em questão. Uma tal norma, pressuposta como a mais elevada, será aqui designada como norma fundamental (Grundnorm) ${ }^{29}$

Essa norma se apresenta, assim, como o fundamento de validade do sistema jurídico, sob um ponto de vista formal, pois fundamenta o sistema a partir dele mesmo, isto é, no nível do sollen, sem precisar de elementos situados no plano do sein, através da distinção, já apresentada, entre condições de validade (estatuição e eficácia) e fundamento de validade do sistema (Grundnorm).

Assim, a norma fundamental cumpre a função epistemológica de autofundamentação do direito no plano do dever-ser, ${ }^{30}$ tornando possível o conhecimento jurídico (ciência do direito) e, ao mesmo tempo, validando a ordem jurídica estatal (função política ou ontológica). Deve-se rememorar que Kelsen, por influência de Bertrand Russell, adota a divisão entre linguagem-objeto e metalinguagem sobre o real, isto é, difere direito positivo de ciência jurídica:

[...] há na TPD, de um lado, o ordenamento jurídico, o que constitui o nível lingüístico n1, e, de outro, a ciência do Direito, o que constitui o nível lingüístico n2. Pois bem, o nível lingüístico n1 possui, como condição fundamental de significação, a última constituição histórica. E o nível lingüístico n2 possui, como condição fundamental de significação, a norma fundamental gnoseológica. ${ }^{31}$

${ }^{29}$ KELSEN, 1979, p. 269.

30 “"...] a norma fundamental como pressuposição lógico-transcedental é um suposto hipotético-cognoscitivo (gnoseológico) que afirma tautologicamente que uma norma é válida porque tem de ser válida". ROCHA, 2003, p. 75.

${ }^{31}$ ROCHA, 2003, p. 75. 
A partir desse quadro, visualiza-se essa dupla função da norma fundamental: validar o direito e tornar possível a ciência jurídica. Entretanto, a Grundnorm representa o ponto maior da TPD no sentido de que fundamenta os dois planos de análise do jurídico (direito positivo, linguagem-objeto, sein) e ciência do direito (metalinguagem, sollen), existindo, assim, um núcleo comum que interliga os dois níveis linguísticos (n1 e n2). Conforme Leonel Rocha:

Porém, além destes dois sentidos, existe também um núcleo comum de validade, que interliga, no nível do conhecimento fenomenologicamente -, o Sein e o Sollen (o nível lingüístico n1 e o n2), constituindo um fundamento de validade simultâneo do ordenamento jurídico e da ciência do Direito. Ou seja, existe um momento mágico em que a norma fundamental é, ao mesmo tempo, o fundamento de validade dos dois níveis lingüísticos: do Sollen e do Sein. ${ }^{32}$

A "pureza" que Kelsen busca com sua teoria parece ficar clara com a pressuposição da norma fundamental, isto é, essa fecharia o sistema jurídico, evitando contatos com outros sistemas (moral, religião política, etc.), além de evitar a busca de fundamentos no plano do ser. Contudo, como já apontado, fundamento de validade do ordenamento é a norma fundamental, sendo a estatuição e a eficácia condições de validade:

Fundamento de validade, isto é, a resposta à questão de saber por que devem as normas desta ordem jurídica ser observadas e aplicadas, é a norma fundamental pressuposta segundo a qual devemos agir de harmonia com uma Constituição efectivamente posta, globalmente eficaz, e, portanto, de harmonia com as normas efectivamente postas de conformidade com esta Constituição e globalmente eficazes. A fixação positiva e a eficácia são pela norma fundamental tornadas condição de validade. ${ }^{33}$

Porém um olhar mais atento por sobre esse jogo de palavras, percebe que eficácia e validade acabam por confundir-se, pois, conforme Kelsen:

32 ROCHA, 2003, p. 75-76.

33 KELSEN, 1979, p. 297. 
As normas de uma ordem jurídica valem (são válidas) porque a norma fundamental que forma a regra basilar da sua produção é pressuposta como válida, e não porque são eficazes; mas elas somente valem se esta ordem jurídica é eficaz, quer dizer, enquanto esta ordem jurídica for eficaz. Logo que a Constituição, e, portanto, a ordem jurídica que sobre ela se apóia, como um todo, perde a sua eficácia, a ordem jurídica, e com ela cada uma das suas normas, perdem a sua validade (vigência). ${ }^{34}$

Fica patente o paradoxo: a Grundnorm fundamenta o ordenamento jurídico (função política ou ontológica): contudo, pergunta-se: quando ela é pressuposta? Kelsen responde: “uma ordem jurídica é considerada válida quando as suas normas são, numa consideração global, eficazes, quer dizer, são de facto observadas e aplicadas". ${ }^{35}$ Quer dizer: a NF fundamenta uma ordem jurídica (somente) na medida em que esta (já) é eficaz (suas regras são observadas por uma determinada comunidade), um evidente paradoxo, que revela alguns pontos de crítica em relação à sua teoria, como a impossibilidade de divisão entre sein e sollen e a consequente função política da TPD.

Todavia, a teoria kelseniana padece de um paradoxo que lhe retira qualquer possibilidade analítica, configurando-se em uma mera tautologia sistemática. Isso porque a norma fundamental meramente explica uma situação de fato já consolidada, i.e., a norma fundamental modifica-se conforme se modifica o poder que garante a eficácia. Assim, a norma fundamental é inútil, porque será determinada pelo poder, e não o contrário. Portanto, a norma fundamental "se torna supérflua, como visto

\footnotetext{
34 KELSEN, 1979, p. 298.

35 KELSEN, 1979, p. 298. "Deve-se observar ainda que não só a validade das normas positivas depende da eficácia, como o próprio fundamento de validade, a norma fundamental, depende da eficácia da constituição. A norma fundamental é a garantia última da separação entre o mundo do ser e o mundo do dever-ser. Ela serve como um mecanismo que isola a normatividade do ordenamento jurídico do contágio dos fatos. Mas o preço que Kelsen pagou para que a norma fundamental não fosse uma abstração a fundamentar outra abstração (uma ordem jurídica imaginária) foi muito alto: como foi visto, somente em relação a uma ordem jurídica eficaz a norma fundamental é suposta. Kelsen, deste modo, atravessa o fosso que ele mesmo cavou entre validade e eficácia". BARZOTTO, 2000, p. 65.
} 
acima: por que há necessidade de uma norma que manda obedecer a alguém que já é obedecido?". ${ }^{36}$

Por exemplo, o disposto no famigerado Ato Institucional no 1 (de 9 de abril de 1964):

[...] A revolução se distingue de outros movimentos armados pelo fato de que nela se traduz não o interesse e a vontade de um grupo, mas o interesse e a vontade de uma Nação [...] A revolução vitoriosa se investe no exercício do Poder Constituinte. Este se manifesta pela eleição popular ou pela revolução. Esta é a forma mais expressiva e mais radical do Poder Constituinte [...] Para demonstrar que não pretendemos radicalizar o processo revolucionário, decidimos manter a Constituição de 1946 [...] Fica, assim, bem claro que a revolução não procura legitimar-se através do Congresso. Este é que recebe deste Ato institucional, resultante do exercício do Poder Constituinte, inerente a todas as revoluções, a sua legitimação [...].

Vê-se perfeitamente que há a tentativa de se criar uma nova ordem, que se basearia em uma espécie de norma fundamental que aqui aparece representada como "vontade da nação", mas que na verdade é o puro poder que, em se estabilizando, vai gerar eficácia para o resto do ordenamento, tornando-o legítimo!

Desse modo, Kelsen, ao fundamentar a validade do sistema jurídico na norma fundamental e a necessidade de pressuposição (validade) desta na eficácia, além de criar um problema epistemológico (confusão do sein com o sollen) ${ }^{37}$ e um "corte" ("fechamento" do sistema) na fundamentação (terceiro ponto do Trilema de Münchhausen ${ }^{38}$ ), cria um problema político, pois a "pureza" da teoria esconde uma função ideológica, porque, se a Norma Fundamental tem a função de transformar o poder em direito (sendo, assim, um médium entre o sein - fatos - e o sollen - sistema

\footnotetext{
36 BARZOTTO, 2000, p. 66, grifo nosso.

37 O que era de se esperar, visto que “[...] a oposição entre ser/dever-ser, base vertebral da TDP, não é uma opção teórica com a qual se pode concordar ou discordar. Ela é impossível! É impossível, porque tal oposição origina toda uma série de dicotomias hoje totalmente superadas pela teoria política, Sociologia e Semiologia contemporâneas: forma/matéria, existência/valor, teoria/práxis, etc.” ROCHA, 2003, p. 78.

38 Ponto que será analisado a seguir pelo fato de ser central para os fins deste artigo.
} 
jurídico) ${ }^{39}$ esta acaba por se torna uma ficção (metafísica), pois é o próprio poder que fundamenta a validade; sendo assim, o topo do ordenamento ocupado não por uma "norma suprema", mas por um "poder supremo".

\begin{abstract}
Além da sua superfluidade, a teoria da norma fundamental falha em determinar as verdadeiras relações entre direito e poder. Segundo Kelsen, a norma fundamental tem a função de transformar o poder em direito. Mas cabe perguntar: o poder necessita da norma fundamental? Não é ele, sozinho, o fundamento do ordenamento jurídico? Kelsen não reconhece, que de fato o poder cria o direito? Por que teria necessidade de uma norma que o autorizasse a isso? E a conclusão não pode ser outra: parece ser mais adequado assumir que no topo do ordenamento tem-se um poder supremo, e não uma norma suprema. ${ }^{40}$
\end{abstract}

Assim, a norma fundamental, e de certa forma toda a Teoria Pura do Direito, não passa de uma querela (positivista-metafísica), pois não é possível (pelo menos a partir da teoria kelseniana) a separação entre serdever-ser entre fatos e direito, teoria e realidade. Além disso, no plano político, cria-se uma abertura para tiranias e ditaduras, pois se as normas desses regimes forem eficazes, não se questionará sua legitimidade, ficando constatado, assim, a função político-ideológica da TPD de modo a criar um direito puramente formal em que tudo que possa ser classificado como direito (código binário Rech - Unrech) e seja eficaz, será válido. É necessário ressaltar, todavia, que Kelsen nunca tivera resvalos autoritários, muito pelo contrário: sempre fora muito preocupado com a democracia, a ponto de publicar obras sobre o tema. ${ }^{41}$

\footnotetext{
39 “O binômio ser/dever-ser, distinção metodológica fundamental do sistema kelseniano, sofre um duro golpe com esse tratamento dispensado à eficácia. Para não assumir de um modo direto que tudo aquilo que é eficaz é também válido, o que seria grotesco, pois estaríamos derivando normas de fatos, Kelsen situa a eficácia na norma fundamental. Desse modo, estaria solucionado o problema de uma transição abrupta entre normas e fatos, logicamente insustentável. Essa transição seria mediada pela norma fundamental. Essa 'converteria' os fatos em direito”. BARZOTTO, 2000, p. 63.

40 BARZOTTO, 2000, p. 66.

${ }^{41}$ Por exemplo, publicou, entre outros escritos. Esencia y valor de la democracia. México: Nacional, 1980.
} 


\section{A Teoria Pura do Direito e o Trilema de Münchhausen}

Vimos que a norma fundamental cumpre função política ao fechar o sistema do direito no plano do sollen, legitimando, assim, o poder estabelecido. Além disso, cumpre, igualmente, uma função epistemológica, podendo-se concluir que a NF tem a função primordial de ponto arquimédico em relação à Teoria Pura. A partir disso, podemos ver que ela se enquadra perfeitamente no Trilema de Münchhausen, mormente na sua terceira alternativa/formulação como apontaremos de forma detalhada.

A (auto)fundamentação do direito a partir da NF configura-se, assim, como um recurso metafísico dogmático de corte/interrupção arbitrário do princípio da fundamentação suficiente, tendo um caráter meramente decisionista e idealista. Lembremos, pois, de Hans Albert quando preceitua a terceira alternativa/forma de fundamentação suficiente: "uma interrupção do procedimento em um determinado ponto, o qual, ainda que pareça realizável em princípio, nos envolveria numa suspensão arbitrária do princípio da fundamentação suficiente". ${ }^{42}$

Seguro afirmar que a norma fundamental, enquanto ponto de interrupção do procedimento de fundamentação, incorre no trilema de Münchhausen em sua terceira alternativa supracitada. De fato, essa conclusão salta aos olhos.

Contudo, pretendemos também identificar até que ponto Kelsen também não acaba por criar uma argumentação circular autofundamentada, em que A é fundamento de B que não fora fundamentado. Isto é

[...] um círculo lógico na dedução, que resulta da retomada, no processo de fundamentação, de enunciados que já surgiram anteriormente, como carentes de fundamentação, e o qual, por ser logicamente falho, conduz do mesmo a nenhuma base segura $[. . .]^{43}$

Isso fica explícito quando temos uma norma fundamental que valida juridicamente um ordenamento que já é considerado jurídico, pois, se assim não o fosse, não se poderia pressupor a NF. Isto é, “a norma

${ }^{42}$ ALBERT, 1976, p. 27.

43 ALBERT, 1976, p. 26. 
fundamental só é suposta diante de um ordenamento jurídico cujas normas são assumidas como válidas", ${ }^{44}$ quer dizer, a norma fundamental somente é pressuposta se já existe uma ordem considerada jurídica e eficaz, um círculo lógico, não fundamentado, pois, se a NF fundamenta o sistema jurídico, e esta só fundamenta um ordenamento eficaz, i. é., que já é jurídico, não se explica qual é a função da NF, nem como ela valida o direito e muito menos qual sua validade.

A validade objetiva da ordem jurídica, diz Kelsen, está apoiada pela hipótese [...] de uma norma suprema, a Grundnorm, mas esta norma não é outra coisa senão a hipótese [...] da validade objetiva da ordem jurídica! A definição em círculo salta aos olhos. ${ }^{45}$

A questão conclusiva é a seguinte: a norma fundamental somente é válida na medida em que fundamenta um ordenamento jurídico válido, quer dizer ela somente fundamenta um ordenamento que já é válido/ jurídico/eficaz! Uma função meramente tautológica. Como aponta Barzotto, "a norma fundamental é válida, e portanto jurídica, se fundar um ordenamento já considerado como jurídico, e portanto, válido". ${ }^{46}$

Enfim, a norma fundamental, como argumento que ao mesmo tempo fundamenta o Direito e a Ciência do Direito, incorre em sérios problemas teóricos, a despeito do fôlego de sua obra. A norma fundamental viu-se, é, ao mesmo tempo, signo representativo de uma argumentação recursiva e circular (o direito tem seu fundamento de validade na norma fundamental: esta, todavia, só fundamenta algo se o ordenamento for válido) e de uma argumentação interruptiva (a fundamentação do ordenamento termina em uma norma fundamental, suficiente nela mesma).

\footnotetext{
44 BARZOTTO, 2000, p. 70.

${ }^{45}$ CONTANTIN STAMATIS apud BARZOTTO, 2000, p. 71.

${ }^{46}$ BARZOTTO, 2000, p. 71.
} 


\section{Conclusão}

A despeito de suas inumeráveis contribuições na seara da dogmática $^{47}$ e da teoria da democracia, ${ }^{48}$ enquanto fundamentação do direito e da ciência do direito, Kelsen é, ao mesmo tempo, prisioneiro de seu tempo e espaço, bem como de suas escolhas teóricas fundamentais.

Kelsen é prisioneiro de seu tempo e de seu espaço ao trabalhar nos marcos do neopositivismo lógico. Não que sua escolha não fosse livre: o marxismo, apesar dos seus defeitos, estava em franco desenvolvimento, possibilitando a construção de conceitos mais agarrados ao meio social. Por outro lado, trabalhos ligados em algum nível ao viés positivista, mas com foco na linguagem, tais como Saussure e Peirce, de alguma maneira já haviam desmontado os ideais neopositivistas de uma linguagem "pura" e unívoca.

Um dos seus pressupostos fundamentais também durou pouco: trata-se da lógica analítico-formal. No início do século XX, o ideal de uma lógica conteudística já havia sido abandonado pelos pensadores sérios. Sobrara, todavia, a lógica formal, ou a estruturação verdadeira de enunciados despidos de conteúdo, mas concatenados enquanto forma. Todavia, até mesmo esta lógica fora atacada pelos desenvolvimentos da filosofia da linguagem, a qual demonstrou que enunciados lógicos, além de não serem universais, uma vez que estão fincados no mundo da vida daquele que os profere, tampouco são livres de conteúdo, uma vez que a situação linguística dos intérpretes no mundo da vida faz com que se antecipe um conteúdo aos enunciados formais, uma vez que, sem conteúdo, eles são despidos de qualquer sentido. Uma interpretação da lei da sociedade, mesmo em nível científico, não prescinde de uma imersão, o que só se dá a partir da admissão da historicidade tanto das proposições quanto do sujeito cognoscente. E compreensão é um processo complexo, significativo, e não derivativo ou subsuntivo.

Falando em nível científico, este é um dos problemas enfrentados por Kelsen. Está-se falando da divisão entre linguagem e metalinguagem,

\footnotetext{
47 Explicitações de conceitos tais como direito subjetivo, atos jurídicos, atos jurídicos de órgãos, etc.

48 Instituições da democracia representativa, partidos políticos, direitos fundamentais, controle de constitucionalidade, etc.
} 
trabalhada por Carnap. Ocorre que uma metalinguagem nunca é a descrição da linguagem, apesar da pretensão de sê-lo: ambas aparecem como unas, porque reciprocamente consideradas. Se fosse possível perceber ligações, mas mesmo assim diferenciá-las teoricamente, não haveria problema. Acontece que todo o edifício teórico rui quando se percebe uma proposição simples, qual seja, a de que uma eventual metalinguagem - criação de uma linguagem artificial unívoca por sobre a linguagem - sempre necessita da linguagem-objeto para parafrasearse, momento em que novamente contamina-se com a plurivocidade e com a historicidade do mundo. Isso sem contar com o fato de que os signos, mesmo os técnicos, são carentes de base conceitual em-si, só aparecendo seu sentido quando inseridos em sintagmas e em uma situação comunicativa pragmática real (ou uma antecipação dela). Em suma, o conhecimento por sobre o direito é tão "contaminado" quanto este. Isso não melindra a possibilidade de existência de um conhecimento válido, muito pelo contrário: é na riqueza do mundo que se pode formar um juízo crítico acerca de um fenômeno.

Kelsen, tão horrorizado que era com os dualismos da metafísica clássica, criou uma nova, de igual monta: baseando-se nos princípios de Hincapié, desenvolveu um substituto para o direito do princípio da causalidade (controverso desde Hume) utilizado nas ciências duras. Tratase do princípio da imputação, ou da lógica do dever-ser. Como a pretensão de Kelsen era fundamentar o direito pelo próprio direito, as proposições de dever-ser não poderiam residir em um ser. Daí a existência de um ponto interruptivo na argumentação: a norma fundamental. Essa escolha infeliz gerou todas as situações paradoxais descritas no texto.

Mais infeliz ainda foi a escolha da norma fundamental como fundamento também do conhecimento acerca do direito. Não que o fundamento do Direito e do conhecimento não vão encontrar-se mais adiante: o que se critica é a autofundamentação, em um só ato, do Direito e da ciência do direito dentro do próprio direito.

Com relação ao fundamento do direito, nos limites do trabalho podese apenas lançar algumas ideias. O direito, como muitas outras coisas do mundo cultural, é fruto de decisão, mas de uma decisão reflexiva e com pretensão de pública. Certas estão desde o início as proposições lançadas pelas ciências sociais: o direito, como instrumento de um fim que não é 
ele mesmo, é criação de uma dada comunidade (que pode ser a mundial - o que não o faz ser universal, não pelo menos no sentido comum da palavra). Essa simples e trivial constatação pragmática, por óbvio, ainda é extremamente lacunosa, motivo pelo qual é necessário agregar vários conceitos, como o de validade através da excelência do conteúdo. Essa empreitada vem sendo levada a cabo por vários autores, dentre os quais destaque-se Habermas.

Essas decisões que vão criando o direito bastam para fundamentálo, mesmo que todas as relações ligadas a essas decisões tenham ainda de ser analisadas e levadas em conta. O que interessa aqui são essas decisões, desimportando o caráter que a elas deem, são fatos sociais, e, como tais, necessitam ser analisados a partir de um referencial teórico construído a partir das ciências sociais (compreensão) e não a partir da lógica. Bem diferente é, portanto, o nível da construção do conhecimento acerca do direito e o da criação do direito no tocante ao nível pragmático.

A filosofia entra na jogada apenas nos últimos passos, enquanto epistemologia construtiva das condições de possibilidade do conhecimento social. A existência de conhecimentos acerca das coisas fundamentase em um ser, que é o argumento trabalhado por Apel, da situação comunicativa. Enquanto pragmático, este argumento não recai no trilema, pois não se pretende nenhuma derivação semântica. A questão é simples: as pessoas, enquanto membros de uma comunidade linguística e histórica, têm de criar condições, mesmo que historicamente influenciadas, de se entenderem no mundo. Essa constatação é, ao mesmo tempo, também antropológica, porque é a partir da criação de um mundo simbólico, um mundo para-si, que as pessoas necessitaram da construção de fenômenos conceituais capazes de gerar um entendimento entre si, saindo, assim, de um estado meramente instintivo a um reflexivo.

Esse ponto de partida pragmático, não arquimédico, de necessidade da construção do entendimento, retroliga-se à questão social e principalmente ao direito, uma vez que uma comunidade histórica tem de entender-se não só acerca de sua visão de mundo e consequências disso para ação, como também tem de criar normas para fazer algo no mundo. Esses processos de criação de entendimentos, muito embora estejam estribados em uma esfera de faticidade do mundo concreto, com suas dificuldades e consensos precários (o que seria um mundo do 
ser), remetem, a partir dos processos de argumentação e reflexão, a uma outra esfera, a da validade, onde a adesão seria motivada pela excelência dos argumentos (uma esfera do dever-ser). Esses processos, todavia, aparecem às costas dos participantes como um só ato, motivo pelo qual essa distinção entre ser e dever-ser não tem valor como diferenciadores de diferentes esferas do conhecimento.

No final das contas, as condições de validade do direito e do conhecimento acerca do direito diferem em seus jogos de linguagem, mas radicam na necessidade fundamental do gênero humano de entender-se.

\section{Referências}

ALBERT, Hans. Tratado da razão crítica. Tradução de Idalina Azevedo da Silva, Érika Gudde e Maria José P. Monteiro. Rio de Janeiro: Tempo Brasileiro, 1976.

BARZOTTO, Luiz Fernando. O positivismo jurídico contemporâneo: uma introdução a Kelsen, Ross e Hart. São Leopoldo: Editora Unisinos, 2000 .

KANT, Immanuel. Crítica da razão pura. São Paulo: Nova Cultural, 2005.

KELSEN, Hans. Esencia y valor de la democracia. México: Nacional, 1980.

KELSEN, Hans. Teoria pura do direito. 4. ed. Tradução de João Baptista Machado. Coimbra: Armênio Amado Editor, 1979.

OLIVEIRA, Manfredo Araújo. Sobre a fundamentação. Porto Alegre: Edipucrs, 1993.

ROCHA, Leonel Severo. Epistemologia jurídica e democracia. 2. ed. São Leopoldo: Editora Unisinos, 2003.

STRECK, Lenio Luiz. Hermenêutica jurídica e (m) crise: uma exploração hermenêutica da construção do direito. 5. ed. Porto Alegre: Livraria do Advogado, 2004. 
WARAT, Luis Alberto. Introdução geral ao direito II: a epistemologia jurídica da modernidade. Tradução de José Luiz Bolzan de Morais. Porto Alegre: Sergio Antonio Fabris Editor, 1995a.

WARAT, Luis Alberto. O direito e sua linguagem. 2. ed. (com a colaboração de Leonel Severo Rocha). Porto Alegre: Sergio Antonio Fabris Editor, 1995b. 